\title{
A novel oxiranylchromenone derivative, MHY336, induces apoptosis and cell cycle arrest via a p53- and p21-dependent pathway in HCT116 human colon cancer cells
}

\author{
SUN HWA LEE ${ }^{1 *}$, YONG JUNG KANG ${ }^{1 *}$, DONG HWAN KIM ${ }^{1}$, BOKYUNG SUNG ${ }^{1}$, JIN AH KANG $^{1}$, \\ PUSOON CHUN ${ }^{2}$, JEONG-HYUN YOON ${ }^{1}$, HYUNG RYONG MOON ${ }^{1}$, HYUNG SIK KIM ${ }^{3}$, \\ $\mathrm{HAE} \mathrm{YOUNG} \mathrm{CHUNG}^{1}$ and NAM DEUK KIM ${ }^{1}$
}

\begin{abstract}
${ }^{1}$ College of Pharmacy, Molecular Inflammation Research Center for Aging Intervention (MRCA), Pusan National University, Busan 609-735; ${ }^{2}$ College of Pharmacy, Inje University, Gimhae, Gyeongnam 621-749; ${ }^{3}$ Division of Toxicology, College of Pharmacy, Sungkyunkwan University, Suwon 440-746, Republic of Korea
\end{abstract}

Received October 18, 2013; Accepted November 21, 2013

DOI: 10.3892/ijo.2013.2226

\begin{abstract}
In this study, we compared cytotoxicity, cell cycle distribution, and apoptosis on MHY336 treatment in three human colorectal carcinoma HCT116 cells: p53 $3^{+/+}$(p53-wt), $\mathrm{p} 53^{-/-}$(p53-null), and p21/- (p21-null), as well as investigated the roles of p53 and p21 in cell death. Using these three isogenic variants, the roles of p53 and p21 in the cellular response to treatment with MHY336, a novel topoisomerase II $\alpha$ inhibitor, were investigated. Our results showed that MHY336 treatment increased the expression of p53 over time in cells with wild-type p53 status. This elevated levels of p53 is associated with increased DNA fragmentation, and cleavage of poly(ADP-ribose) polymerase, consistent with increased sensitivity of these cells to apoptotic stimuli. However, p53-null and p21-null cells were more resistant to the antiproliferative and apoptotic effects of MHY336 than p53-wt cells. The same result was achieved by knocking down p53 and p21 with siRNA in p53-wt cells, indicating that p53 and p21 play a crucial role in MHY336-induced cell cycle arrest and apoptosis. Taken together, these results suggest that MHY336 could be a potential candidate to be used in chemoprevention and/or treatment of colon cancer.
\end{abstract}

\section{Introduction}

Colorectal cancer (CRC) is a result of uncontrolled cell growth in the colon or rectum-parts of the large intestine, or in the

Correspondence to: Dr Nam Deuk Kim, Department of Pharmacy, College of Pharmacy, Pusan National University, 63 Beon-gil 2, Busandaehag-ro, Geumjeong-gu, Busan 609-735, Republic of Korea E-mail: nadkim@pusan.ac.kr

\section{${ }^{*}$ Contributed equally}

Key words: ox iranylchromenone derivative, colon cancer cells, p53, p21, apoptosis, cell cycle appendix. As of $2008 \mathrm{CRC}$ is the second most common cause of cancer in women and the third most common in men (1) with it being the fourth most common cause of cancer death after lung, stomach and liver cancer (WHO, 2013). In Europe the 5-year survival for colorectal cancer is $<60 \%$. In the developed world about a third of the people with this malignancy die from it (2). According to the National Cancer Registry of Korea, age-standardized incidence rates increased from 27.0 to 50.2 per 100,000 for men and from 17.1 to 26.9 per 100,000 for women between 1999 and 2009. The overall incidence of CRC increased in both gender annually from 1999 to 2009, while the incidence rates of the most common cancers, such as stomach and liver cancer, decreased during the same period (Korea National Cancer Information Center, 2013). According to one report, a total of 234,727 new cancer cases and 73,313 cancer deaths are expected in Korea during 2012. Among these cases, 32,215 are CRCs, followed by thyroid, stomach cancer, and 8,195 cancer deaths are CRC-related (3). While $>50 \%$ of CRC patients with surgical resection is cured, $40-50 \%$ of these subjects eventually experience recurrences and the possibility of re-operation is very low (4). Because of high prevalence and poor prognosis of CRC, there is a need to study novel preventive treatment approaches for this malignancy.

Several flavonoids have been shown to interact with purified topoisomerase I and II, suggesting that these compounds may possess anticancer activities (5). It is well known that flavonoid compounds exhibit strong antioxidant activity (6) and topoisomerase II inhibitory effects (7) in the presence of $\mathrm{OH}$ moieties. Patra and colleagues recently reported that MHY336, a novel oxiranylchromenone derivative, showed potent topoisomerase II inhibition through downregulation of topoisomerase II $\alpha$ expression and upregulation of p53 expression in p53 wild-type (p53-wt) LNCaP prostate cancer cells (8). MHY336 is structurally similar to a flavonoid derivative but it has one phenolic hydroxyl group substitution. They also demonstrated that MHY336 markedly induced apoptotic cell death via mitochondria-mediated intrinsic pathway in LNCaP cells. Moreover, the cytotoxicity of MHY336 was more potent 
in p53-wt prostate cancer cells than in p53 mutated (DU145) or deleted (PC3) cells. Even though the role of p53 in the response to chemotherapeutic agents is well established, the relationship between p53-driven genes and drug sensitivity remains unclear. Here, we investigated the role of p53 and its downstream effector $\mathrm{p} 21$, in determining cytotoxicity of the MHY336 treatment in three isogenic variants of human colon cancer HCT116 cells: p53 $3^{+/}$(p53-wt), p53 has functional $\mathrm{p} 21$, and $\mathrm{p} 21^{--}$(p21-null) which has functional p53 (9).

\section{Materials and methods}

Chemicals. MHY336 [5-hydroxy-7-(oxiran-2-ylmethoxy)-2phenyl-4H-chromen-4-one] (Fig. 1) was kindly provided by Professor Hyung Ryong Moon (Laboratory of Medicinal Chemistry, College of Pharmacy, Pusan National University, Korea). MHY336 was dissolved in sterile dimethyl sulfoxide (DMSO) to generate $10 \mathrm{mM}$ stock solution and stored at $-20^{\circ} \mathrm{C}$ until use. Subsequent dilutions were made in RPMI-1640 (Hyclone, Logan, UT, USA). The maximal concentration of DMSO did not exceed $0.1 \%(\mathrm{v} / \mathrm{v})$ in the treatment range, where there was no influence on the cell growth. All other chemicals with the highest purity available were from Sigma-Aldrich Co. (St. Louis, MO, USA).

Cell culture. The human colorectal cancer cell lines HCT116 $\mathrm{p} 3^{+/+}$(p53-wt), p53/- (p53-null) and $\mathrm{p} 21^{-{ }^{--}}$(p21-null) were obtained from American Type Culture Collection (Manassas, VA, USA) and kindly provided by Professor Young-Chae Chang (Department of Pathology, Catholic University of Daegu School of Medicine, Daegu, Korea) (9). These cells were cultured in RPMI-1640 (Hyclone) supplemented with $10 \%$ fetal bovine serum (FBS, Hyclone), $2 \mathrm{mM}$ glutamine (Sigma-Aldrich), $100 \mathrm{U} / \mathrm{ml}$ penicillin (Hyclone), and $100 \mu \mathrm{g} /$ $\mathrm{ml}$ streptomycin (Hyclone) at $37^{\circ} \mathrm{C}$ in a humidified $5 \% \mathrm{CO}_{2}$.

Cell viability assay. Cell viability was determined by MTT assay. For the MTT assay, cells were seeded in a 24-well culture plate at a density of $4 \times 10^{4}$ cells/well, cultured for 24 and $48 \mathrm{~h}$ in the growth media and then treated with or without various reagents for the indicated concentrations. The cells were incubated with $0.5 \mathrm{mg} / \mathrm{ml} \mathrm{3-(4,5-dimethylthiazol-2-yl)-}$ 2,5-diphenyl tetrazolium bromide (MTT, Sigma-Aldrich) at $37^{\circ} \mathrm{C}$ for $2 \mathrm{~h}$. The formazan granules generated by the live cells were dissolved in dimethyl sulfoxide (DMSO), and the absorbance at $540 \mathrm{~nm}$ was monitored by using a multi-well reader.

Annexin V staining. Annexin V-FITC is used to quantitatively determine the percentage of cells within a population that are actively undergoing apoptosis. The cells were treated under the appropriate conditions for $24 \mathrm{~h}$, subsequently harvested, trypsinized, washed once in cold PBS, and suspended in $1 \mathrm{X}$ binding buffer (Becton-Dickinson, San Jose, CA, USA Annexin V-FITC Apoptosis Detection kit). The counted cells were stained in propidium iodide (PI, Sigma-Aldrich) and Annexin V-FITC solution (Becton-Dickinson) at room temperature for $15 \mathrm{~min}$ in the dark. The stained cells were analyzed by flow cytometry within $1 \mathrm{~h}$.

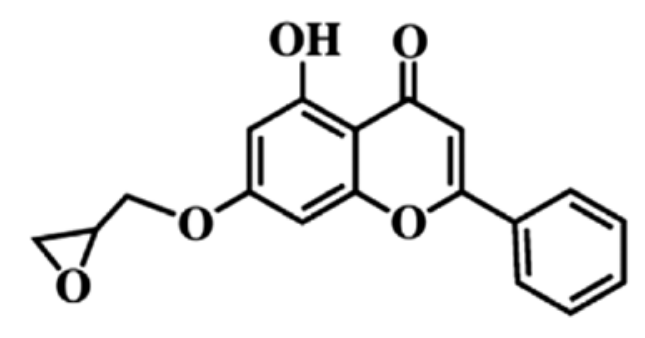

Figure 1. Chemical structure of MHY336 [5-hydroxy-7-(oxiran-2-ylmethoxy)2-phenyl-4H-chromen-4-one].

DNA fragmentation assay. Cells were lysed in a buffer, containing $5 \mathrm{mM}$ Tris- $\mathrm{HCl}(\mathrm{pH} 7.5), 5 \mathrm{mM}$ EDTA and $0.5 \%$ Triton X-100, for $30 \mathrm{~min}$ on ice. Lysates were vortexed and cleared by centrifugation at 14,000 rpm for $20 \mathrm{~min}$. Fragmented DNA in the supernatant was treated with RNase, followed by proteinase $\mathrm{K}$ digestion, phenol:chloroform:isoamyl alcohol mixture (25:24:1) extraction and isopropanol precipitation. DNA was separated through a $1.5 \%$ agarose gel, was stained with $0.1 \mu \mathrm{g} / \mathrm{ml}$ ethidium bromide, and was visualized by $\mathrm{UV}$ source.

Cell cycle analysis. The DNA content was measured following the staining of the cells with PI. The cells were treated under the appropriate conditions for $24 \mathrm{~h}$, subsequently trypsinized, washed once in cold PBS, and then fixed in $70 \%$ ethanol at $-20^{\circ} \mathrm{C}$ overnight. The fixed cells were pelleted and stained in cold PI solution (50 $\mu \mathrm{g} / \mathrm{ml}$ in PBS) at room temperature for $30 \mathrm{~min}$ in the dark. The stained cells were analyzed by flow cytometry (FC500, Beckman Coulter, Istanbul, Turkey).

Western blot analysis. The cells were treated with the appropriate conditions, harvested, and washed with cold PBS. Total cells lysates were lysed in lysis buffer [40 mM Tris ( $\mathrm{pH} 8.0$ ), $120 \mathrm{mM}, \mathrm{NaCl}, 0.5 \% \mathrm{NP}-40,0.1 \mathrm{mM}$ sodium orthovanadate, $2 \mu \mathrm{g} / \mathrm{ml}$ aprotinin, $2 \mu \mathrm{g} / \mathrm{ml}$ leupeptin and $100 \mu \mathrm{g} / \mathrm{ml} \mathrm{PMSF}]$. Protein extracts were denatured by boiling at $100^{\circ} \mathrm{C}$ for $5 \mathrm{~min}$ in sample buffer (0.5 M Tris- $\mathrm{HCl}$, pH 6.8, 4\% SDS, $20 \%$ glycerol, $0.1 \%$ bromophenol blue, $10 \% \beta$-mercaptoethanol). Equal amount of the total proteins were subjected to $6-15 \%$ SDS-PAGE and transferred to PVDF. The membranes were blocked with $5 \%$ non-fat dry milk in Tris-buffered saline with Tween-20 buffer (TBS-T) (20 mM Tris, $100 \mathrm{mM} \mathrm{NaCl,} \mathrm{pH} 7.5$ and $0.1 \%$ Tween-20) for $1 \mathrm{~h}$ at room temperature. Then, the membranes were incubated overnight at $4^{\circ} \mathrm{C}$ with primary antibodies (Santa Cruz Biotechnology Inc., Santa Cruz, CA, USA). The membranes were washed with TBS-T buffer and incubated for $1 \mathrm{~h}$ with horseradish peroxidase-conjugated anti-rabbit or anti-mouse immunoglobin (Santa Cruz). The membranes were washed with TBS-T buffer. Antigen-antibody complexes were detected by the enhanced chemiluminescence (ECL) detection system (GE Healthcare, Little Chalfont, Bucks, UK).

Transient transfection. HCT116 p53-wt cells were seeded in 6-well culture plate in antibiotic-free medium for $24 \mathrm{~h}$ and then transfected with p53- or p21 siRNA using Lipofectamine 2000 


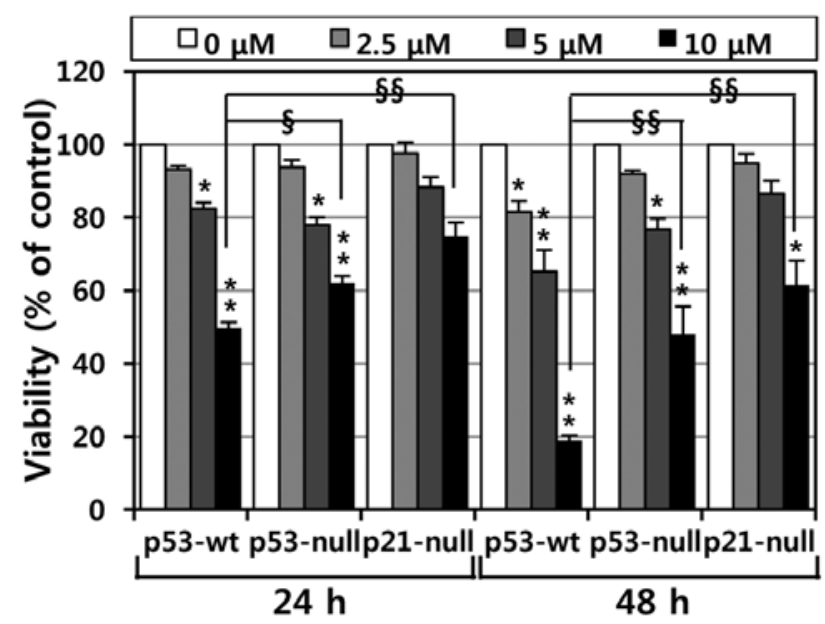

Figure 2. Effect of MHY336 on cell viability of p53-wt, p53-null and p21-null cells. One day after seeding, cells were treated with incremental concentration of MHY336 for 24 and $48 \mathrm{~h}$. Proliferation was measured by using the MTT assay. The results are expressed as mean \pm SE $(n=6)$ and as a percentage of vehicle-treated control. The significance was determined by Student's t-test $\left({ }^{*} \mathrm{p}<0.05\right.$ and ${ }^{* *} \mathrm{p}<0.01$ vs. vehicle-treated control cells and ${ }^{\S} \mathrm{p}<0.05$ and ${ }^{\S \S} \mathrm{p}<0.01$ vs. $10 \mu \mathrm{M}$ MHY336-treated $\mathrm{p} 53-\mathrm{wt}$ cells).

(Invitrogen, Calsbad, CA, USA) according to the manufacturer's protocol. Control siRNA, p53 siRNA and p21 siRNA were obtained from Bioneer (Sungnam, Korea). The sequence of siRNA targeting p53 is: sense, 5'-CACUACAACU ACAUGUGUA-3'; antisense, 5'-UACACAUGUAGUUGUA GUG-3' and p21 siRNA sequence is: sense, 5'-CUGUAC UGUUCUGUGUCUU-3'; antisense, 5'-AAGACACAGA ACAGUACAG-3'. After 6-h transfection, cells were cultured for $24 \mathrm{~h}$ in the growth media and then treated with or without various reagents for the indicated concentrations.

Statistical analysis. Results are expressed as the mean $\pm \mathrm{SE}$ of three separate experiments and analyzed by Student's t-test. Means were considered significantly different at $\mathrm{p}<0.05$ or $\mathrm{p}<0.01$.

\section{Results}

MHY336 has more potent cytotoxicity on p53-wt cells than on p53-null and p21-null cells. To investigate the effects of MHY336 on the viability of p53-wt, p53-null and p21-null cells, the MTT assay was performed. As shown in Fig. 2, MHY336 showed concentration- or time-dependent cytotoxicity on three isogenic variants. Moreover, we found a significant difference in the $\mathrm{IC}_{50}$ among p53-wt, p53-null and p21-null cells. The $\mathrm{IC}_{50}$ values of MHY336 on p53-wt cells were $\sim 10$ and $6 \mu \mathrm{M}$ at 24 and $48 \mathrm{~h}$, respectively. However, the $\mathrm{IC}_{50}$ values of MHY336 were $\sim 15$ and $10 \mu \mathrm{M}$ at 24 and $48 \mathrm{~h}$, respectively in p53-null cells and 20 and $15 \mu \mathrm{M}$ at 24 and $48 \mathrm{~h}$ in p21-null cells, respectively. These results indicate that p53-wt cells were more sensitive to MHY336 than p53-null and p21-null cells.

MHY336 induces morphological changes and apoptosis p53/ p21-dependently. To assess whether there are any morphological changes in MHY336-treated cells, we examined the cells under a phase-contrast light microscope after $24 \mathrm{~h}$ of incubation with or without MHY336. As shown in Fig. 3, MHY336-untreated p53-wt, p53-null and p21-null cells spread regularly in the culture plate and grew to near confluent. In contrast, MHY336-treated p53-wt cells were shrunken and changed to round form. Cell numbers were also decreased in a concentration-dependent manner. MHY336-treated p53-null and p21-null cells did not show any noteworthy morphological changes. To confirm that these changes are attributed to apoptosis induced by MHY336, flow cytometry analysis was performed in three isogenic cells. As shown in Fig. 4A, increase of early apoptosis (lower right quadrant) and late apoptosis/necrosis (upper right quadrant) was clearly observed in a concentration-dependent manner. The late apoptosis of MHY336 on p53-wt cells increased from $4.04 \%$ (vehicle alone) to $26.87 \%$ (10 $\mu \mathrm{M}$ MHY336), whereas MHY336-treated p53-null and p21-null cells did not show any variation. We also analyzed whether DNA fragmentation, another hallmark of apoptosis, occurred in the MHY336-treated isogenic cells. In

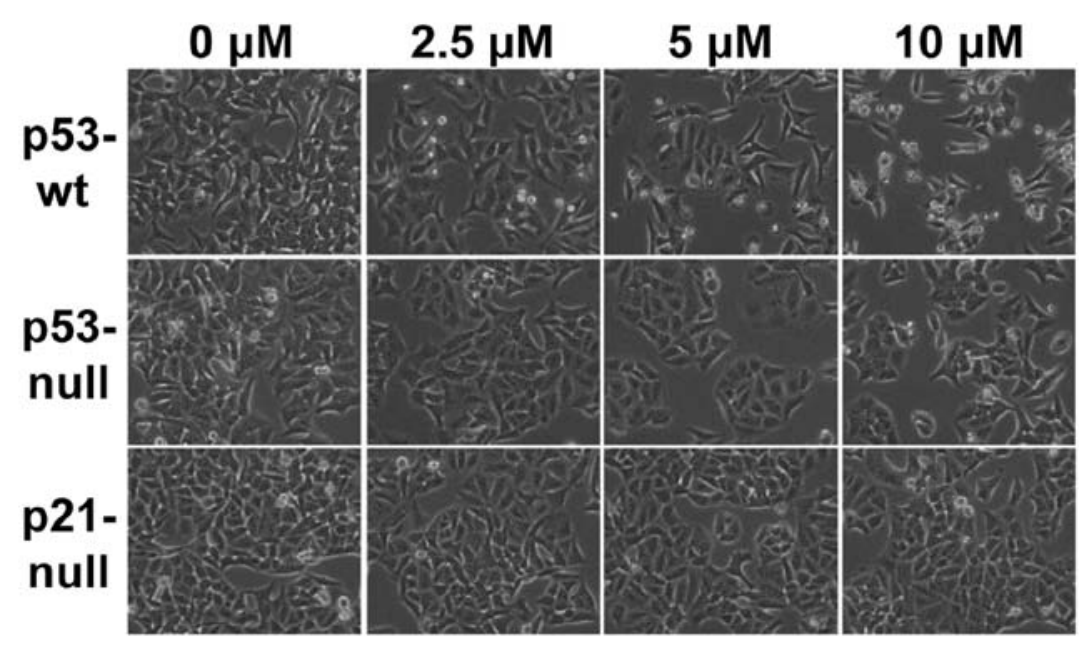

Figure 3. Morphological changes of p53-wt, p53-null and p21-null cells treated with MHY336. Cells were treated for $24 \mathrm{~h}$ with the indicated concentrations of MHY336 and morphological changes were observed by phase contrast microscopy at x400 magnification. 


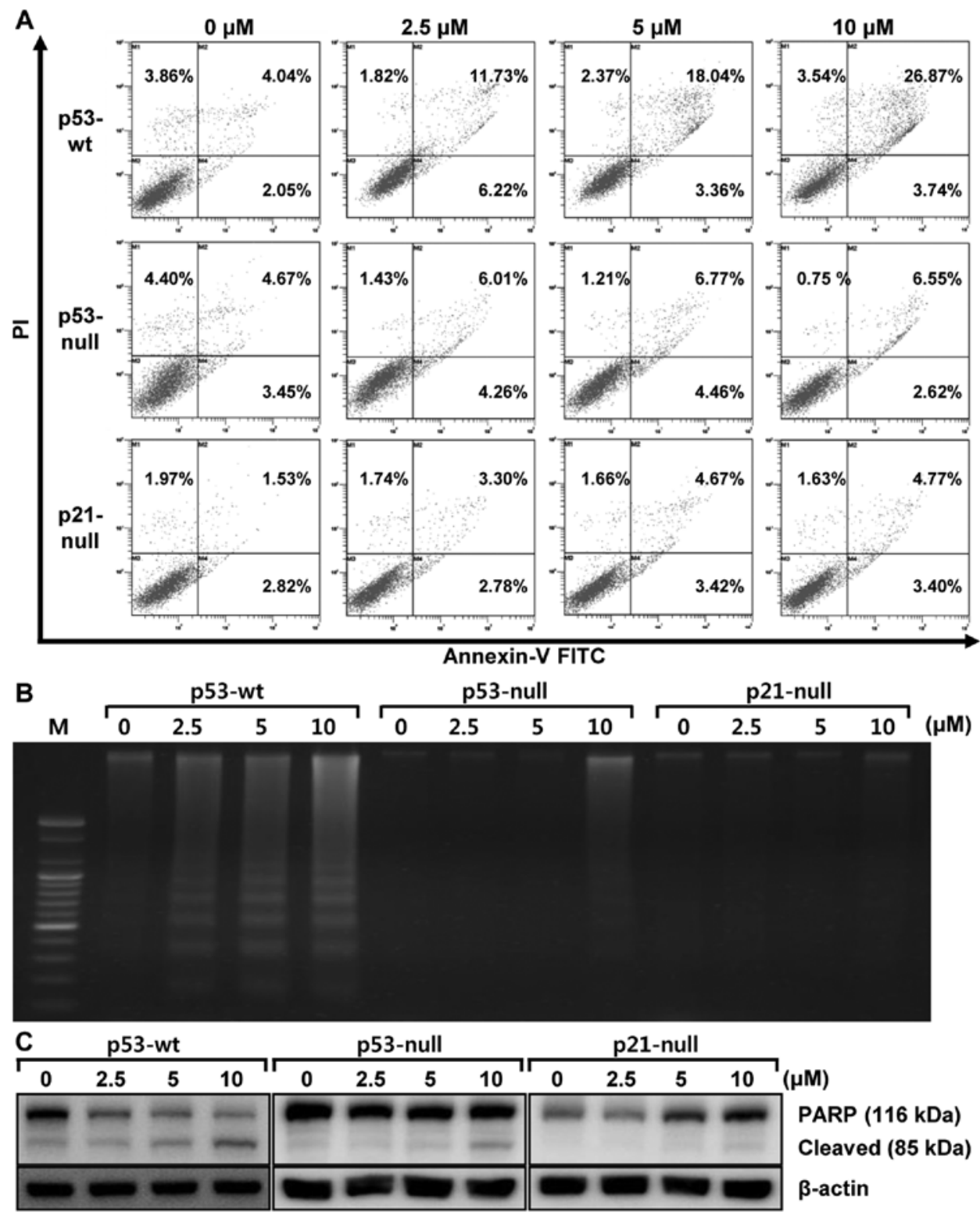

Figure 4. Induction of apoptosis in p53-wt, p53-null and p21-null cells treated with MHY336. (A) To investigate the effect of MHY336 on cell death, cells were treated for $24 \mathrm{~h}$ with the indicated concentrations of MHY336. Annexin V binding and PI uptake in non-permeabilized cells and analyzed with flow cytometry. (B) To analyze fragmentation of genomic DNA, cells were treated for $24 \mathrm{~h}$ with the indicated concentrations of MHY336. DNA was extracted and analyzed by $1.6 \%$ agarose gel electrophoresis in the presence of EtBr. A representative blot is shown from three independent experiments. M, marker. (C) Cells were treated with indicated concentrations of MHY336 for $24 \mathrm{~h}$, collected, lysed and then cellular proteins were separated and immunoblotted. The membranes were probed with PARP $(116 \mathrm{kDa})$. Proteins were visualized using the ECL detection system. Representative results from three independent experiments are shown. Actin was used as a loading control.

p53-wt cells treated with MHY336 for $24 \mathrm{~h}$, there was a typical ladder pattern of internucleosomal fragmentation observed in a concentration-dependent manner after agarose gel electrophoresis (Fig. 4B). On the other hand, DNA fragmentation was not identified in either MHY336-treated p53-null or p21-null cells. Polypeptide degradation, including poly(ADP-ribose) polymerase (PARP), was also examined to see the possible involvement of apoptosis-associated protease during the growth inhibition of the colon cancer cells. PARP cleavage was evident by the appearance of the $\mathrm{p} 85$ PARP cleavage fragment (Fig. 4C) and clearly observed in p53-wt cells at the concentration of 5 and $10 \mu \mathrm{M}$ of MHY336 treatments. MHY336-treated p53-null cells showed lesser amount of the p85 PARP cleavage fragment in the $10 \mu \mathrm{M}$ of MHY336 treatment, but not in p21-null cells. Collectively, these results suggest that p53 and/ or p21 are crucial mediator(s) of MHY336-induced apoptosis.

MHY336 modulates the cell cycle and its regulatory proteins in p53-wt cells. To investigate whether MHY336 has an effect on the cell cycle, we thus only used p53-wt cells. After 24-h incubation with different concentrations of MHY336, p53-wt cells treated with MHY336 were remarkably arrested in the G2/M phase. The proportions of sub-G1 phase cells were increased as well (Fig. 5A). The population of the cells in the $\mathrm{G} 2 / \mathrm{M}$ phase was increased from $19.78 \%$ (vehicle alone) to $38.03 \%$ (10 $\mu \mathrm{M}$ MHY336). The increase of cell population in $\mathrm{G} 2 / \mathrm{M}$ phase was accompanied by the decrease in $\mathrm{G} 0 / \mathrm{G} 1$ cells. In addition, after 24-h incubation with $10 \mu \mathrm{M}$ MHY336, the 


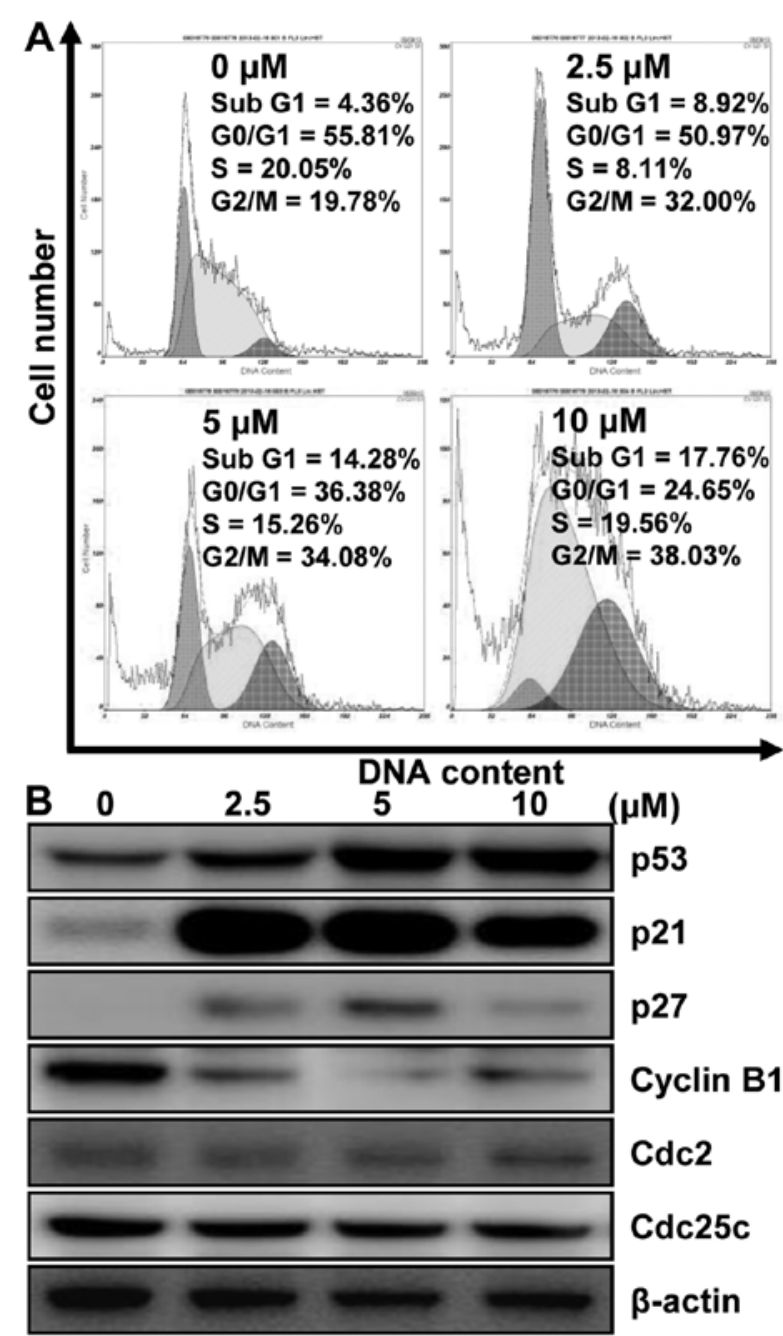

Figure 5. Effects of MHY336 on cell cycle and levels of cell cycle regulatory proteins. (A) Exponentially growing p53-wt cells at $60-70 \%$ confluence were treated for $24 \mathrm{~h}$ with the indicated concentrations of MHY336. The percentages of cells in sub-G1, G0/G1, S or G2/M phases of the cell cycle are indicated within each histogram. (B) To detect the protein levels of cell cycle regulators, the cells were treated with indicated concentrations of MHY336 for $24 \mathrm{~h}$, collected, lysed and then cellular proteins were separated and immunoblotted. The membranes were probed with indicated antibodies for ECL detection. Representative results from three independent experiments are shown. Actin was used as a loading control.

fractions of sub-G1 peak increased from $4.36 \%$ (vehicle alone) to $17.76 \%$ (10 $\mu \mathrm{M}$ MHY336). However, MHY336-treated p53-null and p21-null cells did not show any changes (data not shown). These results supported the MHY336 treatment for 24 h mainly induced the inhibition of cell growth via G2/M phase arrest in the cell cycle. To assess the effect of MHY336 on the intracellular protein expression levels of $\mathrm{G} 2 / \mathrm{M}$ phase in cell cycle, we performed western blot analysis. As shown in Fig. 5B, the expression levels of cyclin B1, Cdc25c and Cdc2 were decreased by MHY336 treatment in a concentrationdependent manner. The induction of p21 is known to cause subsequent arrest in the $\mathrm{G} 1 / \mathrm{G} 0$ or $\mathrm{G} 2 / \mathrm{M}$ phase of the cell cycle by binding of the cyclin-cyclin dependent kinase (CDK) complex. The protein levels of p21 and p27, CDK inhibitors, were increased in p53-wt cells by MHY336 treatment concentration-dependently (Fig. 5B). In addition, protein levels of

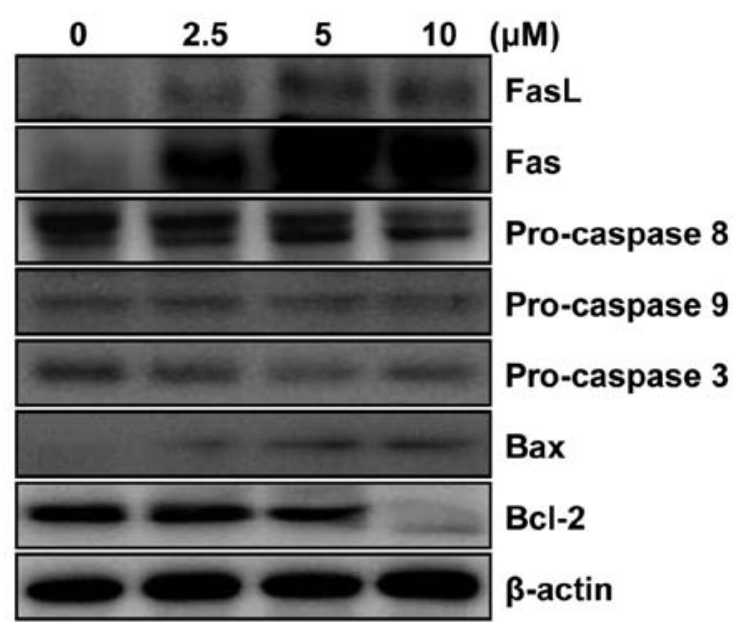

Figure 6. Effect of MHY336 on the expression levels of proteins involved in extrinsic and intrinsic pathways of apoptosis in p53-wt cells. p53-wt cells were treated for $24 \mathrm{~h}$ with the indicated concentrations of MHY336. The expression levels of proteins involved in extrinsic and intrinsic pathways, such as FasL, Fas, pro-caspase-3, pro-caspase-8, pro-caspase-9, Bax and Bcl-2 in p53-wt cells were detected by western blot analysis. Proteins were visualized using the ECL detection system. Representative results from three independent experiments are shown. Actin was used as a loading control.

p53 were also increased. Therefore, these results suggest that MHY336 treatment induces G2/M phase arrest in cell cycle by downregulating expressions of cyclin and CDKs, and by inducing $\mathrm{p} 21$ via p53-dependent pathway.

MHY336 modulates the expression levels of apoptosis-related proteins in p53-wt cells. To determine whether the expression levels of apoptosis-related proteins were modulated by MHY336, western blot analysis was performed. As shown in Fig. 6, the levels of Fas as well as FasL expression were significantly upregulated in a concentration-dependent manner. In addition, significant activation of pro-caspase-3 and -8 was observed, while there was little change in procaspase 9 . The expression level of Bax protein was markedly upregulated, but $\mathrm{Bcl}-2$ was downregulated in concentrationdependent manner. These results, collectively, imply that MHY336 induces apoptosis through both internal and external pathway in p53-wt cells.

p53 and p21 are required for MHY336-induced apoptosis in p53-wt cells. To examine the role of p53 and p21 in MHY336induced apoptosis, we performed knockdown of the p53 or p21 using siRNA in p53-wt cells. As shown in Fig. 7A, p53 siRNA completely inhibited the expression levels of p53 and p21, whereas p21 siRNA suppressed only p21 in p53-wt cells. These results showed that p53 silencing led to abrogation of $5 \mu \mathrm{M}$ MHY336-induced activation of pro-caspase-3 and cleavage of PARP. On the other hand, p21-silencing partially resulted in repression of activation of pro-caspase-3 and 8, and subsequently PARP cleavage. Furthermore, after cells were double stained with Annexin V and PI for apoptosis and necrosis, the results revealed that the p53 knockdown p53-wt cells significantly blocked apoptosis of MHY336 and the p21 knockdown of p53-wt cells incompletely inhibited apoptosis of MHY336 treatment (Fig. 7B). Based on these 


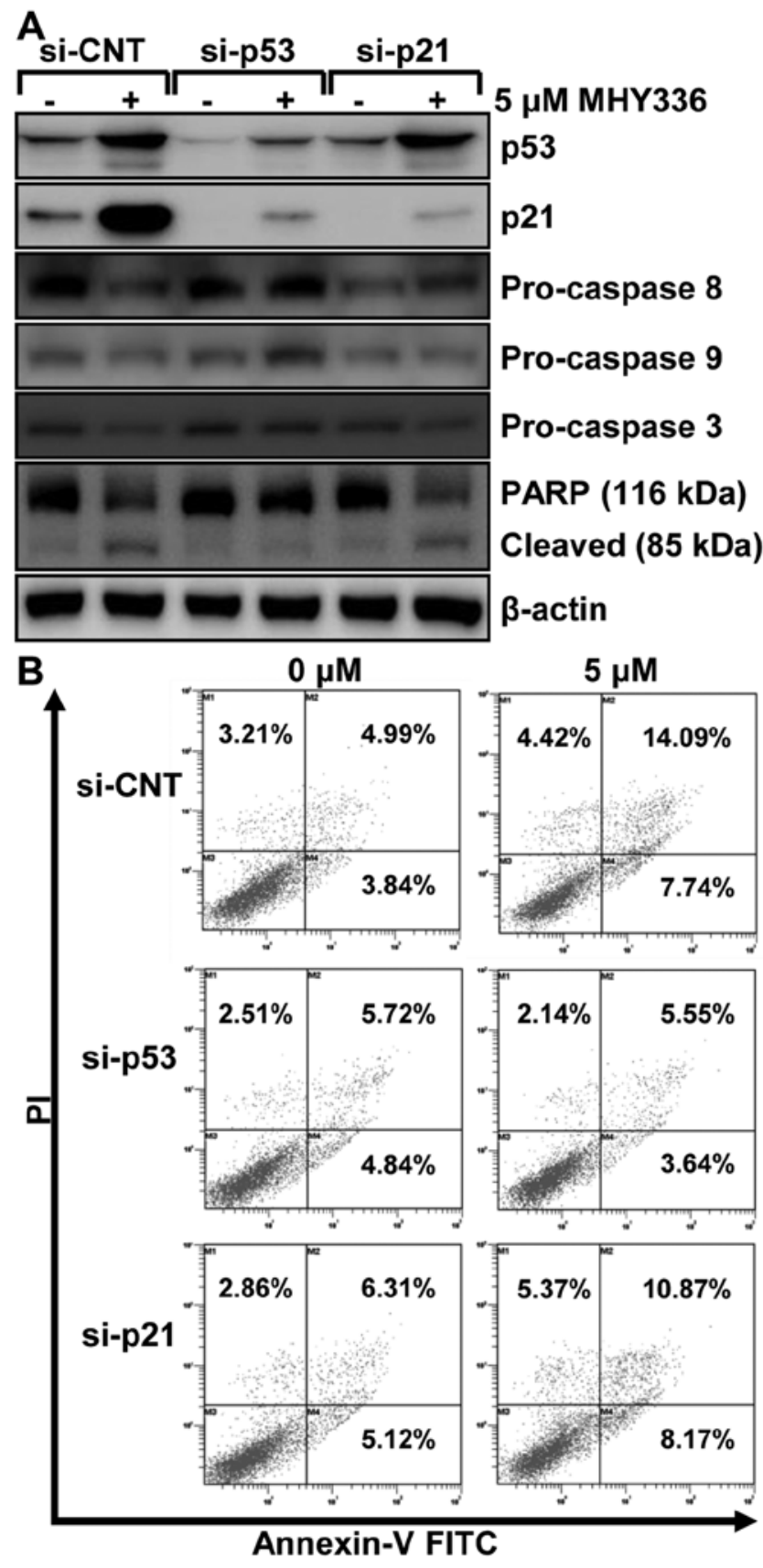

Figure 7. Roles of p53 and p21 in MHY336-mediated apoptosis. (A) p53-wt cells were transfected with a control siRNA (si-CNT), si-p53, and si-21. The cells were treated with $(5 \mu \mathrm{M})$ or without MHY336 for $24 \mathrm{~h}$ and the expressions of various proteins, p53, p21, pro-caspase-8, pro-caspase- 9 , pro-caspase-3 and PARP were analyzed by immunoblotting. Representative results from three independent experiments are shown. Actin was used as a loading control. (B) p53-wt cells were treated with $(5 \mu \mathrm{M})$ or without MHY336 for $24 \mathrm{~h}$ after si-CNT, si-p53 and si-21 transfection. Annexin V binding and PI uptake in non-permeabilized cells and analyzed with a flow cytometry. si-CNT, control siRNA.

data, we suggest that p53 and p21 are important regulators of MHY336-induced apoptosis.

\section{Discussion}

This study was conducted to investigate the role of p53 and its downstream target $\mathrm{p} 21$, in the response of HCT116 colorectal cancer cells to MHY336 treatment. To achieve this goal, we used three isogenic variants of the HCT116 colon cancer cells: p53-wt, p53-null and p21-null. Treatment of p53-wt cells with MHY336 resulted in the maximum apoptotic response whereas p53-null cells were more resistant, and p21-null cells were the most resistant to apoptosis. These results clearly indicate that p53 and subsequently p21 has a pivotal role in sensitization of colon cancer cells to apoptosis in response to cytotoxic agents, such as MHY336. Our data suggest that the increased cytotoxicity in p53-wt cells to MHY336 may be due to the presence of the transcription factor and tumor suppressor p53.

Although the role of p53 as an important mediator of apoptosis is well established under some conditions, the downstream effectors of the p53 pathway in apoptosis are not well known. Several p53-inducible genes which are involved in apoptosis have been identified, such as $m d m-2$ (10), GADD45 (11), $B A X(12)$, and $p 21(13,14)$. Previous evidence suggests that, in addition to cell cycle arrest, p21 may have a role in apoptosis in both p53-dependent and p53-independent pathways $(15,16)$. p53-induced apoptosis results from overlapping downstream pathways that both suppress mitogenic and survival signaling and promote proapoptotic signaling (17). Therefore, p53 can upregulate the proapoptotic Bcl-2 family member Bax (12) and possibly transcriptionally repress the anti-apoptotic protein Bcl-2 (18). Therefore, p53-mediated upregulation of Bax and probably concomitant downregulation of Bcl-2 are pivotal in shifting the ratio of $\mathrm{Bax} / \mathrm{Bcl}-2$ in the cell and ultimately favoring apoptosis.

Normally, p53 plays a major role as both a cell cycle regulator and an inducer of apoptosis in response to a variety of cellular stresses $(8,19)$. As expected, p53-wt cells exhibited a typical G2/M phase arrest via p21, a CDK inhibitor, upregulation and induced apoptosis consequently via both extrinsic and intrinsic pathways as described previously (8). On the other hand, the p53-null cells displayed a loss of the growth-inhibitory and apoptotic effects of MHY336, indicating that the p53 gene plays a crucial role in mediating the effects of MHY336. We also found an absence of p21 in p53-null cells, suggesting the lack of a functional p53 protein could lead to loss of p21 protein levels in response to MHY336 exposure. This was also manifested in a significant reduction of apoptosis in p53-null cells on MHY336 treatment. This study thus suggests that $\mathrm{p} 21$ plays an important role in exerting the apoptotic activity of MHY336 in a p53-dependent manner.

p21, a cyclin-dependent kinase inhibitor, is commonly associated with the G1 checkpoint and G2/M phase, its association with inhibiting the expression of the $\mathrm{Cdc} 2 /$ cyclin B1 complex has been also demonstrated $(20,21)$. p21 transcription can be regulated through p53-dependent (22) and p53-independent pathways (23). In the present study, p21 was increased by MHY336 treatment in p53-wt cells, along with significant increase in the protein levels of p53. Therefore, the upregulation of p21, and the downregulation of cyclin B1, Cdc2, and Cdc25c may be one of the molecular mechanisms by which MHY336 inhibited p53-wt cell growth and induced cell cycle arrest.

p53 stimulates a wide network of signals that act through two major apoptotic pathways. The extrinsic, death receptor pathway triggers the activation of a caspase cascade, and the intrinsic, mitochondrial pathway shifts the balance in the 
Bcl-2 family towards the pro-apoptotic members, promoting the formation of the apoptosome, and consequently caspasemediated apoptosis (24). Wild-type p53 can bind to the specific p53 binding site in the topoisomerase II promoter. During cellular stress or after DNA double-strand breaks, the upregulation of wild-type p53 activates the transcriptional downregulation of topoisomerase II $(8,25-27)$. Therefore, we speculate that MHY336 treatment in p53-wt cells induce DNA damage, which would result in upregulation of p53 and trigger the p53-dependent apoptotic cell death via inhibition of topoisomerase II activity in HCT116 colon cancer cells and $\mathrm{LnCaP}$ prostate cancer cells as previously reported (8).

Apoptosis, a controlled and energy-dependent process, is the best-described form of programmed cell death. There are two major apoptotic pathways, which are the extrinsic pathway and the intrinsic pathway (28). The extrinsic pathway is initiated by the binding of transmembrane death receptors [Fas, tumor necrosis factor receptor 1 (TNFR1), TNF-related apoptosis-inducing ligand (TRAIL) receptors] with cognate extracellular ligands (29). Ligand receptors recruit adaptor proteins [TNFR-associated death domain (TRADD) and Fas-associated death domain (FADD)], which interact with and trigger the activation of caspase-8. Activated caspase- 8 thereby stimulates the effector caspase-3, -6 and -7 which ultimately execute apoptosis (30). The intrinsic pathway is dominated by the Bcl-2 family of proteins which govern the release of cytochrome $c$ from the mitochondria $(31,32)$. Cytochrome $c$ stimulates the apoptosome formation (Apaf-1, dATP, cytochrome $c$ and caspase-9) followed by activation of caspase-9, which in turn causes the activation of the 'executioner' caspases $(-3,-6$ and -7$)(31,33,34)$.

In conclusion, we have clearly shown, using three isogenic variants, that MHY336 induces growth arrest and apoptosis primarily via a p53-dependent pathway that necessarily involves the function of $\mathrm{p} 21$. Taken together, these results suggest that the novel compound MHY336 may be useful in the chemoprevention and/or treatment of colon cancer.

\section{Acknowledgements}

This study was supported by the National Research Foundation of Korea (NRF) grant funded by the Korea government (MSIP) (No. 2009-0083538). We thank Aging Tissue Bank for providing research information.

\section{References}

1. Merika E, Saif MW, Katz A, Syrigos K and Morse M: Review. Colon cancer vaccines: an update. In Vivo 24: 607-628, 2010.

2. Cunningham D, Atkin W, Lenz HJ, et al: Colorectal cancer. Lancet 375: 1030-1047, 2010.

3. Jung KW, Won YJ, Kong HJ, Oh CM, Seo HG and Lee JS: Prediction of cancer incidence and mortality in Korea, 2013. Cancer Res Treat 45: 15-21, 2013.

4. Luu C, Arrington AK, Schoellhammer HF, Singh G and Kim J: Targeted therapies in colorectal cancer: surgical considerations. J Gastrointest Oncol 4: 328-336, 2013.

5. Lopez-Lazaro M, Willmore E and Austin CA: The dietary flavonoids myricetin and fisetin act as dual inhibitors of DNA topoisomerases I and II in cells. Mutat Res 696: 41-47, 2010.

6. Cao G, Sofic E and Prior RL: Antioxidant and prooxidant behavior of flavonoids: structure-activity relationships. Free Radic Biol Med 22: 749-760, 1997.
7. Constantinou A, Mehta R, Runyan C, Rao K, Vaughan A and Moon R: Flavonoids as DNA topoisomerase antagonists and poisons: structure-activity relationships. J Nat Prod 58: 217-225, 1995.

8. Patra N, De U, Kang JA, et al: A novel epoxypropoxy flavonoid derivative and topoisomerase II inhibitor, MHY336, induces apoptosis in prostate cancer cells. Eur J Pharmacol 658: 98-107, 2011.

9. Jeong JH, Kang SS, Park KK, Chang HW, Magae J and Chang YC: p53-independent induction of G1 arrest and p21 $1^{\mathrm{WAF} / \mathrm{CIP} 1}$ expression by ascofuranone, an isoprenoid antibiotic, through downregulation of c-Myc. Mol Cancer Ther 9: 2102-2113, 2010.

10. Oliner JD, Kinzler KW, Meltzer PS, George DL and Vogelstein B: Amplification of a gene encoding a p53-associated protein in human sarcomas. Nature 358: 80-83, 1992.

11. Kastan MB, Zhan Q, el-Deiry WS, et al: A mammalian cell cycle checkpoint pathway utilizing p53 and GADD45 is defective in ataxia-telangiectasia. Cell 71: 587-597, 1992.

12. Miyashita T and Reed JC: Tumor suppressor p53 is a direct transcriptional activator of the human bax gene. Cell 80: 293-299, 1995.

13. Harper JW, Adami GR, Wei N, Keyomarsi K and Elledge SJ: The $\mathrm{p} 21 \mathrm{Cdk}$-interacting protein Cip1 is a potent inhibitor of G1 cyclin-dependent kinases. Cell 75: 805-816, 1993.

14. Xiong Y, Hannon GJ, Zhang H, Casso D, Kobayashi R and Beach D: p21 is a universal inhibitor of cyclin kinases. Nature 366: 701-704, 1993.

15. Waldman T, Kinzler KW and Vogelstein B: p21 is necessary for the p53-mediated G1 arrest in human cancer cells. Cancer Res 55: 5187-5190, 1995

16. Agrawal S, Agarwal ML, Chatterjee-Kishore M, Stark GR and Chisolm GM: Stat1-dependent, p53-independent expression of p21 (waf1) modulates oxysterol-induced apoptosis. Mol Cell Biol 22: 1981-1992, 2002.

17. Aneja R, Ghaleb AM, Zhou J, Yang VW and Joshi HC: p53 and p21 determine the sensitivity of noscapine-induced apoptosis in colon cancer cells. Cancer Res 67: 3862-3870, 2007.

18. Haldar S, Negrini M, Monne M, Sabbioni S and Croce CM: Downregulation of bcl-2 by p53 in breast cancer cells. Cancer Res 54: 2095-2097, 1994.

19. Wang XW and Harris CC: p53 tumor-suppressor gene: clues to molecular carcinogenesis. J Cell Physiol 173: 247-255, 1997.

20. Niculescu AB III, Chen X, Smeets M, Hengst L, Prives C and Reed SI: Effects of p21 (Cip1/Waf1) at both the G1/S and the G2/M cell cycle transitions: $\mathrm{pRb}$ is a critical determinant in blocking DNA replication and in preventing endoreduplication. Mol Cell Biol 18: 629-643, 1998.

21. Baus F, Gire V, Fisher D, Piette J and Dulic V: Permanent cell cycle exit in $\mathrm{G} 2$ phase after DNA damage in normal human fibroblasts. EMBO J 22: 3992-4002, 2003.

22. el-Deiry WS, Tokino T, Velculescu VE, et al: WAF1, a potential mediator of p53 tumor suppression. Cell 75: 817-825, 1993.

23. Gartel AL and Tyner AL: Transcriptional regulation of the p21(WAF1/CIP1) gene. Exp Cell Res 246: 280-289, 1999.

24. Haupt S, Berger M, Goldberg Z and Haupt Y: Apoptosis - the p53 network. J Cell Sci 116: 4077-4085, 2003.

25. Sandri MI, Isaacs RJ, Ongkeko WM, et al: p53 regulates the minimal promoter of the human topoisomerase IIalpha gene. Nucleic Acids Res 24: 4464-4470, 1996.

26. Wang Q, Zambetti GP and Suttle DP: Inhibition of DNA topoisomerase II alpha gene expression by the p53 tumor suppressor. Mol Cell Biol 17: 389-397, 1997.

27. Valkov NI and Sullivan DM: Tumor p53 status and response to topoisomerase II inhibitors. Drug Resist Updat 6: 27-39, 2003.

28. Yang SY, Sales KM, Fuller B, Seifalian AM and Winslet MC: Apoptosis and colorectal cancer: implications for therapy. Trends Mol Med 15: 225-233, 2009.

29. Peter ME: The flip side of FLIP. Biochem J 382: e1-e3, 2004.

30. Ashkenazi A: Targeting the extrinsic apoptosis pathway in cancer. Cytokine Growth Factor Rev 19: 325-331, 2008.

31. Cory S and Adams JM: The Bcl2 family: regulators of the cellular life-or-death switch. Nat Rev Cancer 2: 647-656, 2002.

32. Kuwana T, Mackey MR, Perkins G, et al: Bid, Bax, and lipids cooperate to form supramolecular openings in the outer mitochondrial membrane. Cell 111: 331-342, 2002.

33. Oliver L and Vallette FM: The role of caspases in cell death and differentiation. Drug Resist Updat 8: 163-170, 2005.

34. Iannolo G, Conticello C, Memeo L and De Maria R: Apoptosis in normal and cancer stem cells. Crit Rev Oncol Hematol 66: 42-51, 2008. 